\title{
Billard Hugo (sous la dir.), Dictionnaire des prépas
}

Paris, PUF, 2021, 670 p.

\section{Philippe Boulanger}

\section{(2) OpenEdition}

\section{Journals}

Édition électronique

URL : https://journals.openedition.org/geohist/1645

DOI : 10.4000/geohist. 1645

ISSN : 2264-2617

Éditeur

Association française de la Revue de géographie historique

Référence électronique

Philippe Boulanger, «Billard Hugo (sous la dir.), Dictionnaire des prépas », Revue de géographie historique [En ligne], Comptes-rendus, mis en ligne le 20 juillet 2021, consulté le 26 septembre 2021. URL : http:// journals.openedition.org/geohist/1645; DOI : https://doi.org/10.4000/geohist.1645

Ce document a été généré automatiquement le 26 septembre 2021.

\section{(c) (i) () $\Theta$}

Ce(tte) œuvre est mise à disposition selon les termes de la Licence Creative Commons Attribution Pas d'Utilisation Commerciale - Pas de Modification 4.0 International. 


\section{Billard Hugo (sous la dir.), Dictionnaire des prépas}

Paris, PUF, 2021, 670 p.

Philippe Boulanger

\section{RÉFÉRENCE}

Billard Hugo (sous la dir.), Dictionnaire des prépas, Paris, PUF, 2021, 670 p.

1 Cet ouvrage collectif constitue un outil de travail très pratique pour les étudiants en géographie, histoire et géopolitique. Bien qu'il ne soit pas orienté spécifiquement sur les questions de géographie historique, il n'en demeure pas moins très utile pour comprendre des dynamiques territoriales passées et actuelles, intégrant de multiples thématiques pertinentes.

2 Conduit sous la direction de Hugo Billard, professeur en histoire et géographie en classe préparatoire économique, il se présente, d'abord, comme un dictionnaire comprenant des notions diversifiées et nombreuses. Près de 300 articles sont ainsi accessibles sur des questions d'actualité et des problématiques significatives de notre époque. En témoignent celles d'émergence, de zones grises, de Balkanisation, d'archipel mégalopolitaine, de collier de perles et de thalassocratie. A la fois dictionnaire de géographie, d'histoire et de géopolitique, l'étudiant et le chercheur peuvent consulter de manière efficace le sens de ces notions concrètes et essentielles. Ensuite, la réforme des programmes de l'enseignement secondaire et des classes préparatoires économiques demande de reconsidérer certaines notions bien établies par la valorisation de la géopolitique. La compréhension du monde contemporain inclue d'en saisir les lignes de force et les rivalités entre différents acteurs. Elle prend aussi en compte les dynamiques temporelles sur des temps parfois longs.

3 En somme, l'ouvrage se veut un outil de travail complet, rédigé dans un style d'une grande clarté par un ensemble d'auteurs spécialistes des questions présentées. Au-delà de sa première fonction qui consiste à bien informer les étudiants des classes 
préparatoires, l'ouvrage est aussi un dictionnaire recommandé pour les étudiants de licence ou de master en géographie historique. 